\title{
Chapter 9 \\ Electronic and ICT Solutions for Smart Buildings and Urban Areas
}

\author{
Luca Tamburini \\ University of Trento, Italy \\ Maurizio Rossi \\ University of Trento, Italy \\ Davide Brunelli \\ University of Trento, Italy
}

\begin{abstract}
Nowadays, residential hybrid energy systems are moving from being a pure theoretical exercise to real applications for new urban areas. The growing interest related to the needs of reducing pollution, the phasing out of fossil fuel resources and the need to safeguard the environment, have led to a large number of studies and solutions to reduce fuel consumption and to manage energy sources in a better way, leading to an innovative concept of the city where smart infrastructures are in place. In this chapter we introduce the concept of hybrid energy systems, namely buildings that can exploit both renewable energy sources and the grid. On top of it, a system manager schedules the usage of electrical appliances to minimize the electricity bill while providing peak shaving and load balancing services to utilities and service providers.
\end{abstract}

\section{INTRODUCTION}

A city becomes smart whenever investments in ICT referred to human and social capital ensure sustainable economic progress, a high quality of life and an efficient management of natural resources (Seisdedos, 2012). Indeed, with the term smart city we define a set of urban planning strategies aimed at optimizing and innovating public services in such a way as to connect infrastructures with human/intellectual/social capital. This result can be achieved thanks to new communication technologies, mobility innovations and environmental safeguards/energy efficiency:

DOI: 10.4018/978-1-4666-8282-5.ch009 
the common objective is to improve the quality of life, satisfying the needs of citizens, businesses and institutions. A marked line between smart cities and digital cities can be defined, due to the profound difference between a city which leverages on environmental \& social capital and a city with a huge technological infrastructure. Urban performances are not only measured with the pure presence of infrastructures, but also with the availability and quality of communication, knowledge and social infrastructures which determine urban competitiveness.

The expression Smart city is frequently used in different contexts. In economics, it describes smart industry, and especially industries related to ICTs in different forms. Moreover, smart city can be used in regard to the education of its inhabitants: a smart city definitely has smart citizens. In other cases it can be referred to associate governments, administrations and their citizens: "e-governance" and "e-democracy" are increasingly popular and widely-used terms these days. Furthermore, smart city is associated with modern transport technologies, i.e. smart systems capable of improving urban traffic and mobility. Finally, aspects related to quality of life are often associated with the word smart, in connection to sustainability, green energy and security in general terms. Above all, the level of innovation and problem-solving capabilities define smart cities: ICT technologies are the most important means of improving these characteristics. In this way, smartness is somehow an internal quality of a place, city or region in which innovation processes are simplified through information and communication technologies. The smartness level is mainly defined according to people, cooperation systems, digital infrastructures and the means provided by the community to citizens.

In this context, a pillar infrastructure of a smart city is the power distribution grid. When power distribution infrastructures exploit ICT for improving overall efficiency and sustainability, we can refer to them as fundamental components in the larger domain, better known as Smart Grids.

Smart cities and smart grids are strictly correlated: the majority of existing smart cities can leverage on smart grid technologies, including mostly energy-oriented objectives. While smart cities can make the user aware of energy efficiency and savings, smart grid components provide infrastructures capable of connecting different elements of the city itself.

A smart grid is based on a concept of bidirectional electricity flow where buildings can also generate and store electric energy, while some years ago they were simply supposed to be consumers. Now, the local generation of electric power could potentially transform households into energy producers and hybrid electrical residential systems could become a source of earnings and not only used for saving money. A smart grid must facilitate the optimal management of the load (offering demand-side management and other ancillary services), exploiting the information processed from the meter, and should avoid energy waste, overload and voltage drops.

Moreover, smart grids impact positively on single user premises: home environments, in the majority of the world, are isolated energyconsuming units lacking in sustainability and efficiency. Now, in a smart city, intelligent grids can interact directly with the end users in their dwellings, contributing to saving energy and to using it in a more efficient way. In such a vision, smart houses can be considered as active elements of a smart grid (Gungoretal., 2012). A smarthouse (Ricquebourg et al., 2006) can be considered as a residential building equipped with devices (such as smart meters or smart energy controllers) which are coordinated to achieve a common set of goals for the end users. Communication and metering/ measuring technologies are crucial in this kind of scenario, making it possible to achieve the best 
26 more pages are available in the full version of this document, which may be purchased using the "Add to Cart" button on the publisher's webpage: www.igi-global.com/chapter/electronic-and-ict-solutions-for-smart-buildingsand-urban-areas/130966

\section{Related Content}

City Makers: Insights on the Development of a Serious Game to Support Collective Reflection and Knowledge Transfer in Participatory Processes

Teodora Iulia Constantinescu, Oswald Devisch and Georgi Kostov (2017). International Journal of EPlanning Research (pp. 32-57).

www.irma-international.org/article/city-makers/186791

Communicative Planning Theory Following Deliberative Democracy Theory: Critical Pragmatism and the Trading Zone Concept

Raine Mäntysalo and Karoliina Jarenko (2014). International Journal of E-Planning Research (pp. 38-50). www.irma-international.org/article/communicative-planning-theory-following-deliberative-democracy-theory/108869

The Use of Geo-Questionnaire in Spatial Planning: Experience From Poland

Edyta Bkowska-Waldmann and Tomasz Kaczmarek (2019). International Journal of E-Planning Research (pp. 45-67).

www.irma-international.org/article/the-use-of-geo-questionnaire-in-spatial-planning/223969

Engaging Users for Participating in a European Data Collection Campaign with Smartphones Marian Gogola, Eva Malichová and Martin Hudák (2022). International Journal of E-Planning Research (pp. 1-19).

www.irma-international.org/article/engaging-users-for-participating-in-a-european-data-collection-campaign-withsmartphones/309381

Urban Information Systems and Digital Channels to Enhance Transparency and Participation in Urban Planning

Beatriz Santos (2020). Citizen-Responsive Urban E-Planning: Recent Developments and Critical

Perspectives (pp. 83-110).

www.irma-international.org/chapter/urban-information-systems-and-digital-channels-to-enhance-transparency-andparticipation-in-urban-planning/253483 